\title{
Devastato, G. (2017). The Pianist Composer. Da Vinci Classics.
}

\section{Da Vinci Classics C00026}

La faceta interpretativa de un compositor es un factor decisivo en el legado de cada uno de los autores que forman parte de la historia de la música. Al fin y al cabo, el dominio técnico resulta fundamental para extraer las máximas posibilidades de un instrumento en la creación de una obra nueva. A este respecto, la selección del legado de una serie de compositores que, además, destacaron como intérpretes de teclado durante su vida es el primer rasgo distintivo del último disco del pianista y compositor napolitano, afincado en España, Giuseppe Devastato (1977).

En este trabajo discográfico, Devastato interpreta una selección de obras concebidas para piano y otras composiciones que, a pesar de haber sido escritas originalmente para órgano o música de cámara, proceden del legado de compositores que fueron, además, pianistas u organistas destacados y que cuentan, en estos casos, con arreglos para piano elaborados por virtuosos de los siglos XIX y XX.

Aunque, en el libreto, el propio intérprete señala la voluntad de que el álbum incluya una "profunda homogeneidad de formas y esencias musicales gracias a un programa ecléctico", cabe destacar que la selección musical contenida en la presente novedad discográfica presenta, a priori, dos rasgos destacados. Por un lado, se observa una esencia predominantemente italiana y, de forma específica, napolitana. Esta circunstancia se debe a los orígenes del propio Giuseppe Devastato pero también a la esencia performativa del intérprete, que no solo es uno de los artistas italianos más laureados y galardonados en el ámbito internacional, sino cuyo estilo abandera los principios de la histórica Escuela Pianística Napolitana. Por otro lado, la calidad técnica y la delicadeza, características de todas sus interpretaciones, están presentes en la selección musical que Devastato ofrece en The Pianist Composer.

El disco comienza con un homenaje a Johann Sebastian Bach (1685-1750) a través de la interpretación pianística del coral "Ich ruf zu dir, Herr Jesu Christ" BWV 639. Desde el punto de vista creativo, cabe decir que, originalmente, la cantata Ich ruf zu dir, Herr Jesu Christ (BWV 177) fue compuesta en 1732 sobre himnos de Johannes Agricola (1494-1566), uno de los reformadores protestantes. La obra fue concebida por Bach en cinco movimientos para tres solistas (soprano, contralto y tenor), un coro mixto de cuatro voces y una pequeña agrupación instrumental con bajo continuo. Sin embargo, posteriormente el coral de esta cantanta -el primero de los números-, fue adaptada para órgano solo e 


\section{RESEÑAS DE DISCOS}

incluido como BWV 639 en el Orgelbüchlein. Como apertura de la producción discográfica que nos ocupa, Giuseppe Devastato ha seleccionado el arreglo para piano realizado por Ferruccio Busoni (1866-1924), uno de los grandes pianistas italianos del último tercio del siglo XIX y del primer tercio del siglo XX, que también destacó como compositor y fue especialmente laureado por sus adaptaciones pianísticas del legado bachiano. La riqueza armónica y tímbrica de la obra original de Bach se une a las máximas posibilidades técnicas y expresivas del piano propuestas por Busoni a través del intérprete.

A continuación, Devastato aborda una versión pianística de dos números de Myrthen, Op. 25, de Robert Schumann (1810-1856). En este caso, se ha optado por seleccionar un arreglo del pianista napolitano Sergio Fiorentino (1927-1998) de los números 1, "Widmung", y 7, "Die Lotosblume". Cabe decir que Myrten acoge un conjunto de Lieder compuestos por Schumann en 1840 sobre textos de poetas de elevada calidad literaria, como Rückert (1788-1866), Goethe (1749-1832) o Heine (1797-1856). La fecha de composición, en relación con el género del Lied, no resulta, en absoluto, arbitraria, pues 1840 fue el año de su matrimonio con Clara Wieck (1819-1896) y una fecha muy prolífica en la escritura de canciones para voz y piano, de acuerdo con las posibilidades amorosas derivadas de la convivencia de la literatura y de la música. El lirismo, originalmente patente en la melodía vocal de la obra de Schumann, se mantiene en el arreglo de Fiorentino y resulta absolutamente evocador a través de las manos de Giuseppe Devastato, pues una de las características de su pianismo consiste en la imitación de la voz humana a través del piano, inspirado por el arte del Bel Canto napolitano.

La cuarta pista del disco nos invita a realizar un sugestivo viaje a través de las Trois mélodies, Op. 7, para voz y piano, de Gabriel Fauré (1845-1924). En concreto, es interpretada la primera de estas canciones, "Après un rêve", escrita originalmente para voz y piano sobre la adaptación libre de un poema italiano por parte del poeta francés Romain Bussine (1830-1899). La evocación original de la obra, una de las más célebres de Fauré, se mantiene a través de la delicada adaptación, nuevamente, de Fiorentino y de la deliciosa interpretación de Devastato.

Posteriormente, se realiza un acercamiento al legado de Sigismund Thalberg (18121891), quien vivió sus casi dos últimas décadas de vida en Nápoles. Recordemos que Thalberg fue uno de los más destacados pianistas del siglo XIX, el fundador de la Escuela Pianística Napolitana y uno de los instauradores de la aplicación de las posibilidades de la técnica vocal a la interpretación pianística propios de la citada Escuela, uno de los rasgos del intérprete del presente disco. En este caso, Devastato interpreta, con su habitual sensibilidad y lirismo, la primera de las obras que componen L'art du chant appliqué au piano Op. 70, "Quatuor de l'opéra I puritani de Bellini”, una pieza que mantiene el material melódico original de la citada ópera de Bellini (1801-1835) rodeada de las máximas posibilidades expresivas del piano, con un gran control de los matices por parte del pianista.

Una nueva ópera es recreada a través de la siguiente interpretación, en este caso a través del legado de Theodor Leschetizky (1830-1915), pianista y compositor polaco, 


\section{RESEÑAS DE LIBROS}

discípulo de Czerny (1791-1857) y maestro de Paderewksi (1860-1941), entre otros. En concreto, Devastato aborda, con gran maestría, su Andante-Finale da Lucia di Lammermoor para la mano izquierda Op. 13, rescatando, de este modo, la célebre obra de Donizzeti (17971848). Resulta una interpretación absolutamente deliciosa de una obra de una gran complejidad técnica y marcada expresividad.

El disco que nos ocupa no solo recoge trabajos de los compositores más renombrados, sino que también supone el reconocimiento a obras de autores más desconocidos. Es el caso de Vladimir N. Drozdov (1882-1960), que, a pesar de su desconocimiento para el gran público, fue un destacado pianista y pedagogo ruso con visibilidad también en Estados Unidos desde 1923, fecha de su emigración. Au tombeau de Rachmaninov, contenida en la séptima pista del disco, no solo significa un homenaje por parte de Drozdov al célebre Serguei Rachmaninov (1873-1943), sino un alarde de expresividad minimalista por parte del compositor y de sutileza y sentimentalismo por parte del propio intérprete. Por su parte, la octava pista, correspondiente con una nueva obra de Drozdov, contiene Impromptu, que contrasta con la anterior pieza del mismo autor por su vitalismo pero que mantiene el interés melódico y la expresividad romántica.

Aunque Rachmaninov destacó como pianista y compositor para este instrumento, en el presente disco se recuperan varios de sus Romances. Por un lado, Giuseppe Devastato interpreta "How Fair This Spot", de los 12 Romances, Op. 21, a través de un arreglo de Vyacheslav Gryanov (1982). Aunque en la obra original de Rachmaninov el piano no se limita a un mero acompañamiento musical, en esta adaptación del número 7 del $O p$. 21 se apela a las posibilidades pianísticas para abordar también el rico material melódico originalmente concebido para la voz, caracterizado por su gran expresividad en una canción dedicada a una misteriosa persona aludida como "N".

Posteriormente, la obra discográfica presenta otras dos adaptaciones de romanzas de Rachmaninov, en este caso a partir de transcripciones pianísticas realizadas por el propio Devastato en las pistas 10 y 11. Cabe destacar que ambos números seleccionados están compuestos en tonalidad menor y dedicados a mujeres. El lirismo y la delicadeza están presentes por igual en "Vocalise", el número 14 de las 14 Romances, Op. 34, dedicado a la soprano rusa Antonina Nezhdanova (1873-1950), y en "Sing Not to Me, Beautiful Maiden”, el número 4 de los 6 Romances, Op. 4, dedicado, éste último, a su esposa Natalia Alexandrovna Rachmaninov y de especial interés armónico y lírico.

La penúltima obra del disco corresponde es la Romanza "Hommage a Mozart" a la maniere de Ravel, compuesta por el propio Giuseppe Devastato y galardonada con la Medalla de Plata de los Global Music Awards 2014 (Los Ángeles). A pesar de tratarse de una composición creada en el siglo XXI, la convivencia en el disco con los testimonios musicales previamente comentados mantiene la coherencia estética y expresiva. Asimismo, destaca el interés en relación con su escritura, combinando "la aparente simetría mozartiana con una sofisticación modular, armoniosa y ecléctica" -en palabras del propio compositor e intérprete- y la sublime interpretación del propio autor.

El CD finaliza con una nueva obra de Thalberg, incidiendo en el espíritu propio de la Escuela Pianística Napolitana como broche. En este caso, es interpretada la Fantasia on 


\section{RESEÑAS DE DISCOS}

Verdi's La traviata, Op. 78, donde Giuseppe Devastato alcanza las máximas cotas de dificultad en torno a los motivos más característicos de la célebre ópera de Giuseppe Verdi (1803-1901), sin perder un ápice del control técnico, de la pasión y de la expresividad que son propias del estilo del intérprete.

Finalmente, y tras todo lo expuesto, podemos afirmar que Giuseppe Devastato ofrece un alarde técnico a partir de un depurado estilo y de la aplicación de las posibilidades técnicas del canto al piano propias de la histórica Escuela Napolitana en el disco The Pianist Composer. Así, la complejidad técnica de la interesante selección musical presentada en esta producción discográfica es solventada con la habitual maestría y delicadeza del maestro Devastato.

\section{Virginia Sánchez Rodríguez}

Universidad de Castilla-La Mancha

ORCID iD: https://orcid.org/0000-0001-8071-2937 